\title{
Study of diurnal cycle of convective precipitation over Amazonia using a single column model
}

\author{
Alan K. Betts \\ Atmospheric Research, Pittsford, Vermont, USA \\ Christian Jakob ${ }^{1}$ \\ European Centre for Medium-Range Weather Forecasts, Reading, UK \\ Received 5 March 2002; revised 6 June 2002; accepted 24 June 2002; published 14 December 2002. \\ [1] The error in the diurnal cycle of precipitation over land in the tropics in the \\ European Centre for Medium-Range Weather Forecasts forecast model is investigated \\ using a single column model with idealized forcing of the omega field, as well as \\ short-term and long runs of the full three-dimensional model. The model precipitates a \\ few hours after sunrise, as it does not represent correctly the morning development of a \\ growing cumulus boundary layer. In the single column model, precipitation is closely \\ linked to the mean forcing and surface evaporation, but the phase of diurnal varying \\ omega forcing in relation to the diurnal solar cycle determines the relation of convective \\ to large-scale precipitation in the control model, as well as cloudiness and the net \\ radiation balance. With diurnal subsidence peaking at midnight, but no mean ascent, the \\ model shows a quasi 2-day precipitation mode. With both strong mean ascent and \\ diurnal forcing, ascent peaking in the daytime gave stratiform rain with large cloud \\ cover and very low surface net radiation, while daytime subsidence and ascent at night \\ gave strong daytime convective precipitation and high net radiation. INDEX TERMS: 3307 \\ Meteorology and Atmospheric Dynamics: Boundary layer processes; 3314 Meteorology and Atmospheric \\ Dynamics: Convective processes; 3322 Meteorology and Atmospheric Dynamics: Land/atmosphere \\ interactions; KEYWORDS: convective parameterization, precipitation, diurnal cycle, single column \\ model, Amazonia
}

Citation: Betts, A. K., and C. Jakob, Study of diurnal cycle of convective precipitation over Amazonia using a single column model, J. Geophys. Res., 107(D23), 4732, doi:10.1029/2002JD002264, 2002.

\section{Introduction}

[2] The impetus for this study was to understand the error in the diurnal cycle of convective precipitation over land in the European Centre for Medium-range Weather Forecasts (ECMWF) forecast model. Convective precipitation occurs too early in the diurnal cycle in the model: in midlatitudes close to local noon [Betts et al., 1998, 1999; Stendel and Arpe, 1997] and over Amazonia only a few hours after sunrise [Betts and Jakob, 2002]. This diurnal phase error has persisted despite changes in the land-surface and convection schemes and can be seen in the recent 40-year reanalysis [Betts and Viterbo, 2002]. Given the extensive datasets from the Large-scale Biosphere-Atmosphere Experiment (LBA) wet season campaign in Rondônia in 1999 [Silva Dias et al., 2002; Halverson et al., 2002; Petersen et al., 2002; J. A. Marengo et al., On the diurnal and day-to-day variability of rainfall in southwest Amazonia during the TRMM-LBA and LBA-WET AMC campaign of

\footnotetext{
${ }^{1}$ Now at Bureau of Meteorology Research Centre, Melbourne, Victoria Australia.

Copyright 2002 by the American Geophysical Union. 0148-0227/02/2002JD002264\$09.00
}

the summer of 1999, submitted to Journal of Geophysical Research, 2002], our hope was that by understanding the nature of the model error, we might develop, using a single column model (SCM), an improved convective parameterization scheme, which would give the correct diurnal cycle of precipitation when coupled to the global model. So far we have not succeeded, but in the process we have learnt a great deal about the coupled aspects of the model physics involved, and the use of SCMs, which we report in this paper.

[3] Research into the development of convective parameterizations in large-scale models has a long history. They were originally introduced in numerical models to control moist instability arising from saturation on the model gridscale [Manabe and Strickler, 1965; Kuo, 1965]. Only as the finest model horizontal resolutions have become of order five $\mathrm{km}$, has it become possible to explicitly represent moist convection in limited area nested nonhydrostatic models [e.g., Liu et al., 1997]. For practical purposes, global forecast and climate models will need parameterizations to represent dry and moist convection for many years to come. However despite years of research [see Emanuel and Raymond, 1993] and some dedicated field programs, progress on this "parameterization problem" has been slow. A 
major unresolved issue is the coupling between processes of different spatial scales, and the temporal evolution of convective systems. In the diurnal cycle over land, there is often a clear temporal evolution. After sunrise, a growing convective boundary layer (BL) first erodes the nocturnal stable layer. In the ECMWF model this is parameterized as a turbulent process, with diffusion coefficients in the unstable layer prescribed as a similarity profile [Holtslag and Boville, 1993], and BL-top entrainment represented as $20 \%$ of the surface buoyancy flux [Beljaars and Betts, 1993]. The moist tropical atmosphere in Rondônia is close to saturation at the surface at sunrise, so shallow BL cumulus clouds quickly form at the top of a nearly well-mixed subcloud layer. In the model this nonprecipitating cloud process is represented by a mass flux parameterization [Tiedtke, 1989] with a closure representing moist static energy balance in the subcloud layer at each time step. In Rondônia, the BL cloud field deepens steadily on most days, and the radar echoes are usually first seen near 1100 local time (LT) as the first cumulus congestus clouds develop [Silva Dias et al., 2002; Rutledge et al., 2000]. The subsequent development is quite rapid as cumulonimbus form, and organize into convective bands, with maximum rainfall usually about 1400-1500 LT [Negri et al., 2002; Betts et al., 2002]. The mesoscale bands have unsaturated downdrafts, which bring down cooler drier air into the BL at the end of the daytime diurnal cycle, and precondition in part the BL for the next day's convection. The model however fails to represent properly this sequential development of the convection, which lasts some 6-8 hours. As soon as the nocturnal stable BL is eroded about 2 hours after sunrise, the model deep convective parameterization (a mass flux scheme, with a convective available potential energy closure [see Gregory et al., 2000]) finds a cloud-top in the upper troposphere (because the lower troposphere is very unstable up to the freezing level near $550 \mathrm{hPa}$ ), and there is a sharp peak of convective rain, usually at 8-9 LT [Betts and Jakob, 2002]. The model does not represent the growing convective $\mathrm{BL}$, the congestus phase or the development of mesoscale convective bands, nor does it properly simulate the overstabilization of the BL associated with convective downdrafts. Does it matter that the diurnal cycle of precipitation is in error, given that Betts and Jakob [2002] also showed that the mean daily precipitation in the rainy season is roughly correct (as did Betts et al. [1998, 1999] for summer convective precipitation over the Mississippi basin)? It does, because the convective clouds, convective heating and large-scale vertical motion field are closely coupled in the tropics. In addition, the diurnal phase of the cloud fields with respect to the solar cycle directly impacts the short wave radiation budget, and hence the equilibrium surface temperature (the short-wave cloud feed-back in the climate model sense).

[4] The diurnal cycle of convection is forced by the surface fluxes and in addition in the tropics by primarily mean vertical advection. In the rainy season, the mean tropospheric motion is upward in middle troposphere, but there is also a significant diurnal cycle in the vertical motion, which is coupled to the convection, so it is unclear whether the scale separation envisaged by the single column simulations is really useful. SCMs have been used to develop convective parameterizations for some time [Betts and Miller, 1986; Zhang and McFarlane, 1995;
Randall et al., 1996, 2002; Ghan et al., 2000; Wu and Moncrieff, 2001; Sud et al., 2001]. However, in an SCM the vertical motion (or the diabatic forcing) must be specified. Our only knowledge of the diurnal cycle of the vertical motion field (the model omega field) over Amazonia comes itself from the model analyses or from model forecasts, all of which incorporate the model convective parameterization, and all of which have a known error in the diurnal cycle of precipitation and convective heating (see below). The diurnal cycle in the model, as we shall show in the next section, has mean descent peaking near 0800LT, the time of the spurious morning precipitation peak, which suggests the model omega field is not directly the cause of the model precipitation error. However we do not know a priori whether the phase of the model diurnal cycle of the omega field is correct, and therefore useful as forcing for an offline SCM.

[5] We shall first (in section 2) show the model diurnal cycle of precipitation from 3-D forecasts (both short-term and long runs), and SCM runs constrained by large-scale forcing extracted from 3-D short-term forecasts for a gridpoint in Rondônia (near $10.57^{\circ} \mathrm{S}, 62.37^{\circ} \mathrm{W}$, see Betts and Jakob [2002]). Then we show the mean diurnal cycle of vertical motion in the control 3-D model. The two versions of the 3-D model we use differ only in resolution (T-95 for the long runs and T-319 for the short-term forecasts). The model cycle is CY22R3, which includes the new tiled land-surface scheme, introduced in June, 2000 [Van den Hurk et al., 2000]. For technical reasons, the SCM runs are a single column version of an earlier ECMWF model cycle, CY21R4. The only significant difference is that this model cycle uses the previous land-surface scheme of Viterbo and Beljaars [1995]. However, studies have shown that the different land-surface schemes have no impact on the diurnal cycle precipitation error over Amazonia in the rainy season.

[6] In section 3, we will sidestep the unresolved issue of whether the 3-D model omega field is realistic by investigating the response of an SCM version of the full model code to idealized forcing in which we changed the amplitude and phase of an imposed omega field. This shows the complex response of the model physics to the coupling between the omega forcing, the solar forcing and the convection schemes.

\section{Diurnal Cycle in the Model}

\subsection{Diurnal Cycle of Precipitation From the 3-D Model and SCM Runs Using Large-Scale Forcing From 3-D Model}

[7] Figure 1 compares the diurnal cycle of total precipitation from the control model for the Rondônia gridpoint from:

1. An average of the 12-36 hour forecasts [extracted from 48 hour forecasts of the control model, run at T-319] verifying on DOY (day of year) 30-58.

2. An average for days 30-58, extracted from a T-95 global forecasts with the control model initialized on DOY 20, 1999.

3. An average of $12-36$ hour simulations using the SCM of the control model constrained by large-scale forcing extracted from the 3-D T-319 forecast for the Rondônia 


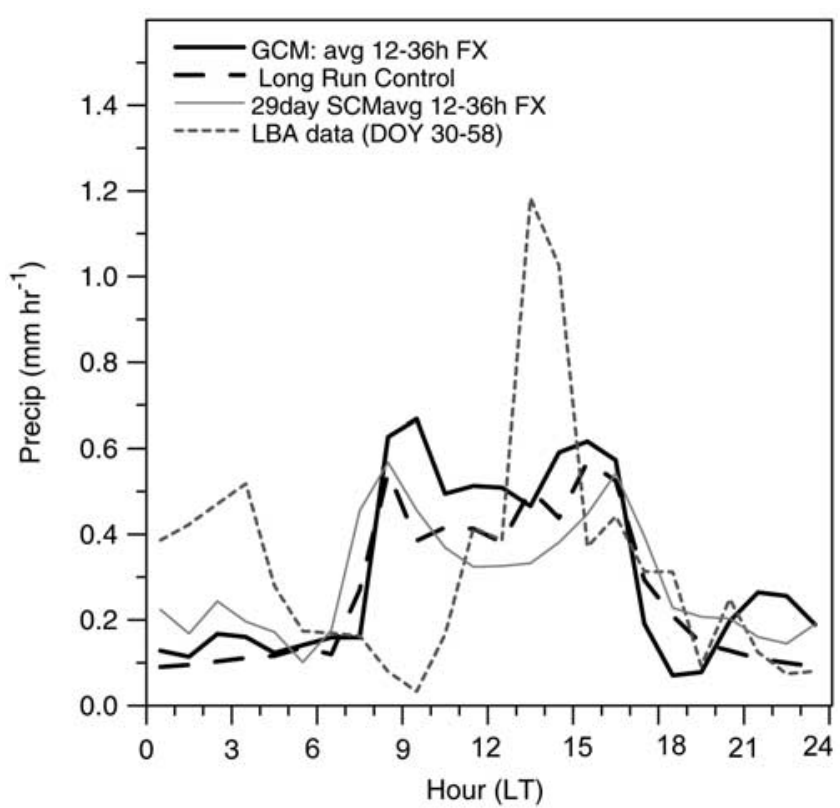

Figure 1. The 29-day mean diurnal cycle of precipitation from short-term forecasts, long run, and SCM runs using large-scale forcing from the 3-D model.

point. (Note that the forcing was extracted from the GCM three-hourly only. Linear interpolation is used to specify the forcing at intermediate times.)

4. An average of the LBA rain nets for DOY 30-58 [from Betts and Jakob, 2002].)

[8] We see that all versions of the control model give an early morning precipitation peak (the $x$ axis is local time, LT) and a second peak in the late afternoon, whereas the characteristic feature of the observations is a morning minimum in rainfall and a midafternoon maximum. The diurnal precipitation structure from the 12-36 hour forecasts of the 3-D model is very similar (although a little higher) than that from the $12-36 \mathrm{hr}$ forecasts from the
SCM model. This suggests that the SCM may be a useful (although simplified) version of the full 3-D model for the study of the behavior of a parameterization scheme. The long-run average of the 3-D model (at lower resolution) also has a double- peaked precipitation structure, similar to the short-term forecasts. This confirms that this error signature is a characteristic of the model, and not any initial conditions.

\subsection{Mean Vertical Motion in Control Model}

[9] The large-scale forcing in the 3-D model is dominated by the vertical motion field. A key issue in the tropics is the phasing of the mean vertical motion of the $3-\mathrm{D}$ model in relation to the phase of the diurnal cycle, since this has a large impact on cloudiness and precipitation. Figure 2 shows the mean diurnal cycle of the omega field for the 29-day average (DOY 30-58) from the high resolution short-term forecasts for the Rondônia grid-point. The vertical co-ordinate is model level, with level 30 corresponding to about $207 \mathrm{hPa}$, level 40 to the freezing level near $550 \mathrm{hPa}$ and level 60 being about $10 \mathrm{~m}$ above the surface. Approximate heights corresponding to selected model levels are shown on the right: note that the model has 10 levels below $1 \mathrm{~km}$. Mean motion is up [omega negative] with a peak at 1700 LT (2100 UTC), and the peak in subsidence is a little before 0800 LT (1200 UTC). The daily mean motion is upwards in the middle troposphere, which is consistent with this being the rainy season and precipitation exceeding evaporation. Figure 1 shows two rainfall peaks. The spurious morning peak is at the time of the maximum subsidence, so it is clear that this is not a direct response to this larger scale forcing, and must arise indirectly from the model parameterizations. The model cloud cover is in fact a minimum at the time of this morning subsidence (not shown). The afternoon precipitation maximum is not long before the time of peak mean ascent (and a maximum of cloudiness in the model, not shown) and the coupling of the two is more apparent.

[10] Figure 3 shows the corresponding mean diurnal cycle for the long integration with the control model. The pattern

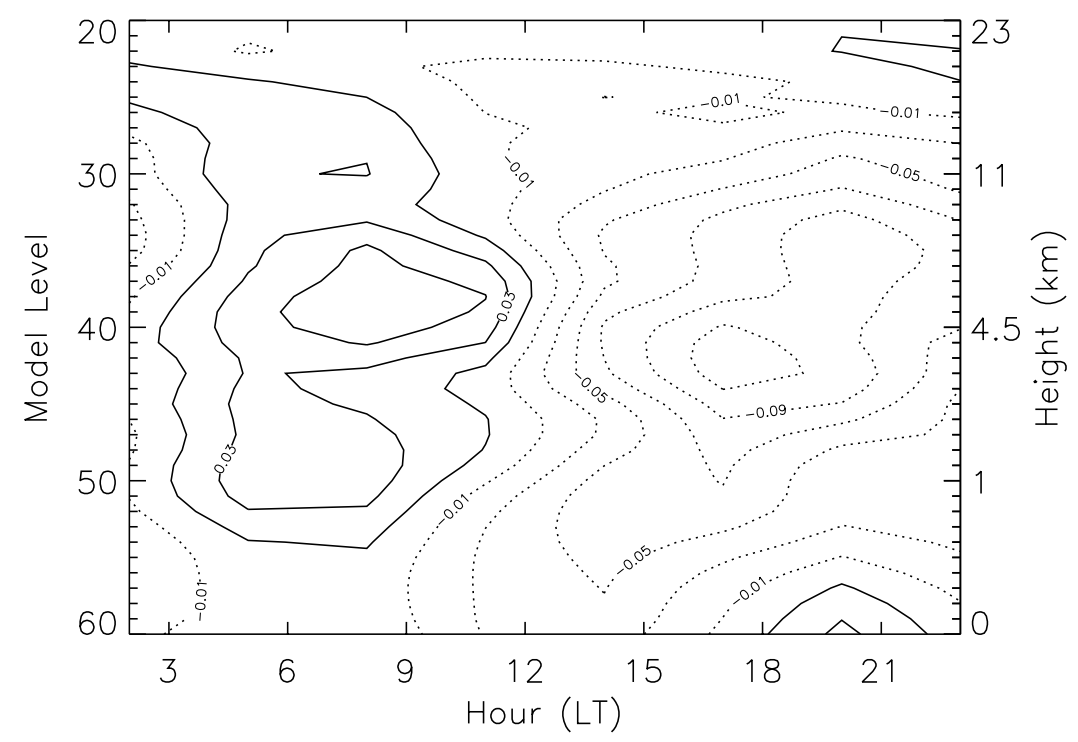

Figure 2. Mean diurnal cycle of omega field for 29-day average from short-term forecasts (in $\mathrm{Pa} \mathrm{s}^{-1}$ ). 


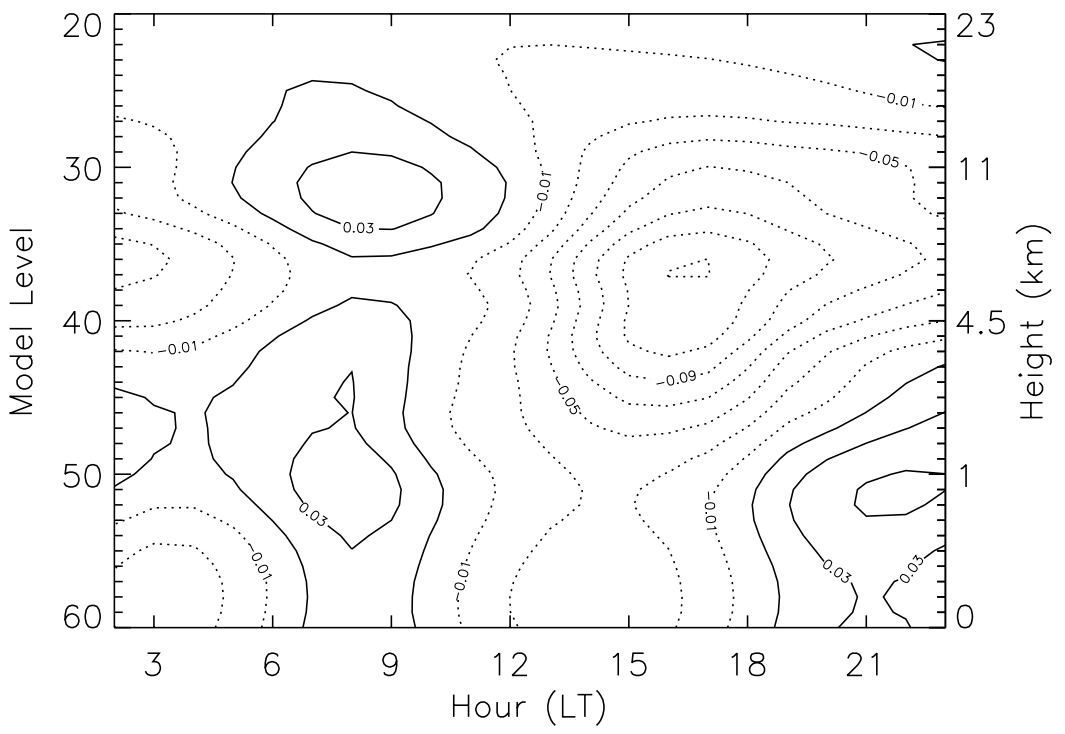

Figure 3. Mean diurnal cycle of omega field for DOY 30-58 from long 'Control' run (in $\mathrm{Pa} \mathrm{s}^{-1}$ ).

is similar to Figure 2, although there is more subsidence in the low levels at night. Thus it seems that the pattern shown in Figure 3 is a stable feature of the 3-D model, although it is not necessarily "correct".

[11] This is important because we use the forcing from the 3-D model offline to drive the SCM. The SCM runs in Figure 1 produce a similar diurnal cycle of precipitation to the 3-D model, and our main conclusion is that the omega field is not the cause of the model morning precipitation maximum, but the SCM is a useful tool to study this model error.

\section{Impact of Idealized Forcing on SCM Runs of the Control Model}

[12] The control model is an SCM version of ECMWF model cycle CY21R4, as mentioned above. As a baseline case, which is shown on many plots, we ran the SCM for 15 days with only the diurnal forcing of the sun, that is, no large-scale vertical motion or advection are prescribed. We then specified as additional forcing an omega field, sinusoidal in time with period one day and a variable phase; single wave number in the vertical with a zero at the surface and at model level 30 (about $207 \mathrm{hPa}$ ), and a maximum in the middle troposphere. To simulate mean upward ascent in the rainy season, we allowed the possibility of an offset in the mean vertical motion. Thus the specified omega forcing was given by

$$
\begin{aligned}
\Omega= & \Omega_{\mathrm{R}}(\mathrm{M}+\mathrm{A} \cos (2 \pi(\mathrm{UTC}-4-\Phi) / 24) \\
& \cdot \cos \left(2 \pi\left(\mathrm{p}-\mathrm{p}_{\mathrm{T}}\right) /\left(\mathrm{p}_{0}-\mathrm{p}_{\mathrm{T}}\right)\right)
\end{aligned}
$$

with a reference amplitude $\Omega_{\mathrm{R}}=0.05 \mathrm{~Pa} \mathrm{~s}^{-1}$ (about $50 \mathrm{hPa}$ day $^{-1}$ ), a range of values of $\mathrm{A}=0,1,2,4$ giving the amplitude of the sinusoidal vertical motion field, $\mathrm{M}$ of 0 and 1 (giving mean upward motion). The phase of the diurnal wave was varied in steps of 3 hours. UTC- 4 corresponds to local time (LT). The phase $\Phi$ is the local time of maximum subsidence: that is phase $\Phi=0$ gives maximum descent (omega positive) at local midnight and maximum ascent at local noon, while $\Phi=6,12$, and 18 correspond to maximum midtropospheric descent at sunrise, noon and sunset, with maximum ascent 12 hours later. Figure 4 shows this idealized omega forcing for $\Phi=0, \mathrm{M}=0$, and $\mathrm{A}=2$ (the slight asymmetry is a plotting artifact, arising from the model using forcing specified every 3 hours in UTC, with linear interpolation in between; while for convenience, we are plotting all figures in LT, which is UTC-4). All horizontal advective forcing terms were set to zero for simplicity. Our baseline case represents $M=A=0$.

[13] Our initial aim was to see if periodic diurnal forcing would give a periodic diurnal cycle, especially of precipitation, and how it might be linked to the phase of the forcing. Our standard forced SCM run was 15 days, and in many graphs we shall show the average of days 2-15, excluding day 1 to reduce the dependency on the initial condition. The initial condition for a gridpoint in Rôndonia (at $10.75^{\circ} \mathrm{S}, 62.37^{\circ} \mathrm{W}$ ) was taken from a 29 -day average (for DOY30-58) of the 12-h forecast of the global model run from each 1200 UTC analysis. We found that because of the strength of the nonlinear interactions between the deep and shallow convection schemes and the radiation scheme, a periodic diurnal response was frequently not the result. Deep convection in this very unstable regime often had rather a stochastic nature, while with stronger forcing, and specific phasing, the response could have a near 2-day periodicity, or in other cases the model SCM would cloud over entirely, and drift to a cooler overcast regime. This led us to look at the relation between phase of forcing, the net radiation budget, evaporation and precipitation.

\subsection{Coupling Between Precipitation, Evaporation, and Radiation Budget}

[14] Figure 5 shows a scatterplot of the 14-day mean surface net shortwave flux $\left(\mathrm{SW}_{\text {net }}\right)$, net radiation $\left(\mathrm{R}_{\text {net }}\right)$, latent heat flux (LH) and total daytime cloud cover (righthand scale) plotted against the 14-day mean total precipitation for $\mathrm{M}=0$ (no mean ascent), $\mathrm{A}=0,1,2$ and 4 and phase $\Phi$ running from 0 to 21 in steps of 3 hours. Not 


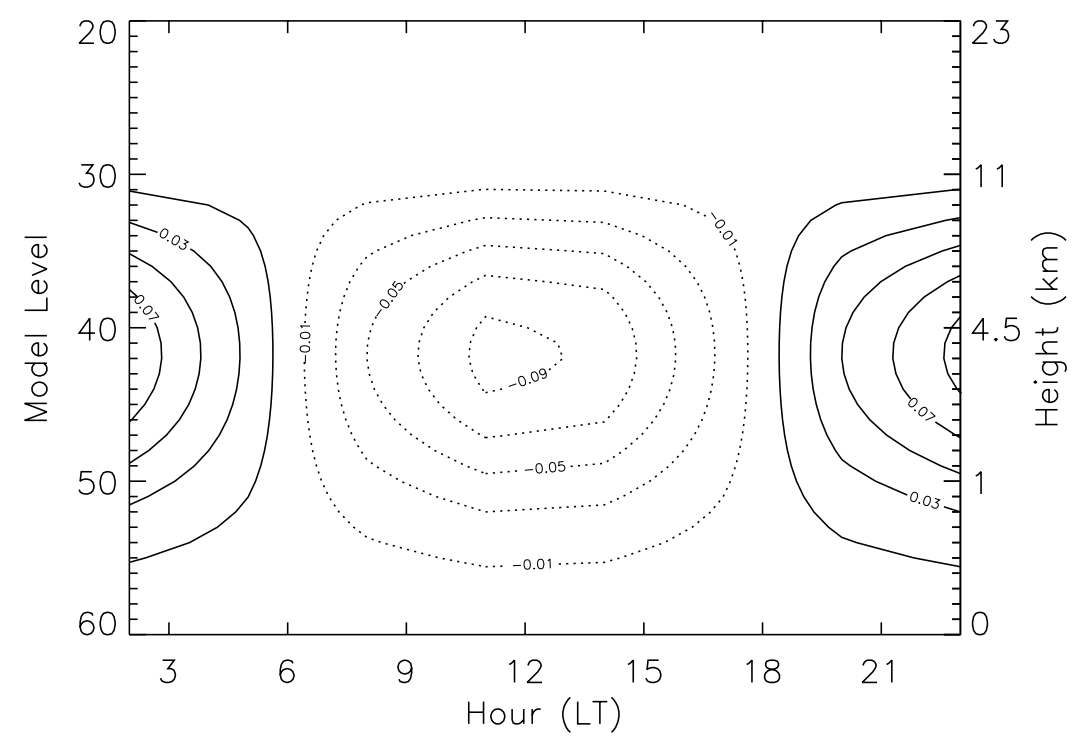

Figure 4. Idealized omega forcing of $\mathrm{SCM}$ for $\Phi=0, \mathrm{M}=0$, and $\mathrm{A}=2$ (in $\mathrm{Pa} \mathrm{s}^{-1}$ ).

surprisingly, precipitation, evaporation, $\mathrm{R}_{\text {net }}, \mathrm{SW}_{\text {net }}$ all increase together, and increasing net radiation is loosely coupled with reduced daytime cloud cover. The best correlation is between precipitation and evaporation. The dotted line is the numeric conversion of precipitation in $\mathrm{mm}$ to an energy flux in $\mathrm{W} \mathrm{m}^{-2}$. Clearly without mean forcing, the mean surface evaporation quite closely controls mean precipitation, since the mean moisture storage is small. There is however, considerable variation in both, related to the surface net radiation. What we are seeing is a nontrivial and nonlinear feedback between convection, cloud, radiation, and surface processes, which is at the heart of the diurnal cycle problem. In the absence of mean ascent, the total precipitation is (on average) entirely determined by the surface evaporation, which in turn strongly responds to the incoming solar radiation. In high cloud cover situations, the solar forcing will be weak, inhibiting large

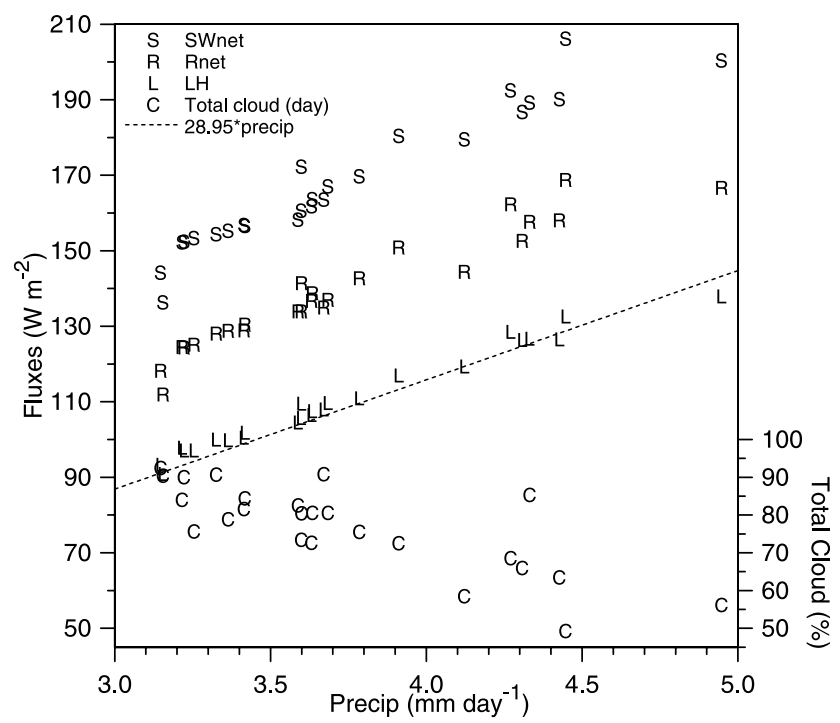

Figure 5. Scatterplot of 14-day mean radiation fluxes, latent heat flux, and total daytime cloud cover against precipitation. evaporation and hence convection. The higher values of cloud cover result from increased stratiform cloud formation in the ascending phase of the prescribed forcing. So depending on the forcing phase, the model finds equilibria along the lines depicted in Figure 5. When stratiform cloud cover is low, precipitation is predominently convective. For the highest cloud covers shown in Figure 5, model precipitation is approximately half convective and half stratiform (not shown). We shall return to this partition later in section 3.8.

\subsection{Impact of Phasing on Precipitation}

[15] Figure 6 shows the 14-day mean total precipitation (evaporation, not shown, looks very similar) for the same SCM runs plotted against the phase for increasing diurnal forcing amplitude $\mathrm{A}=0,1,2,4$. The phase $\Phi$ represents the time of maximum descent in the diurnal cycle. The dotted

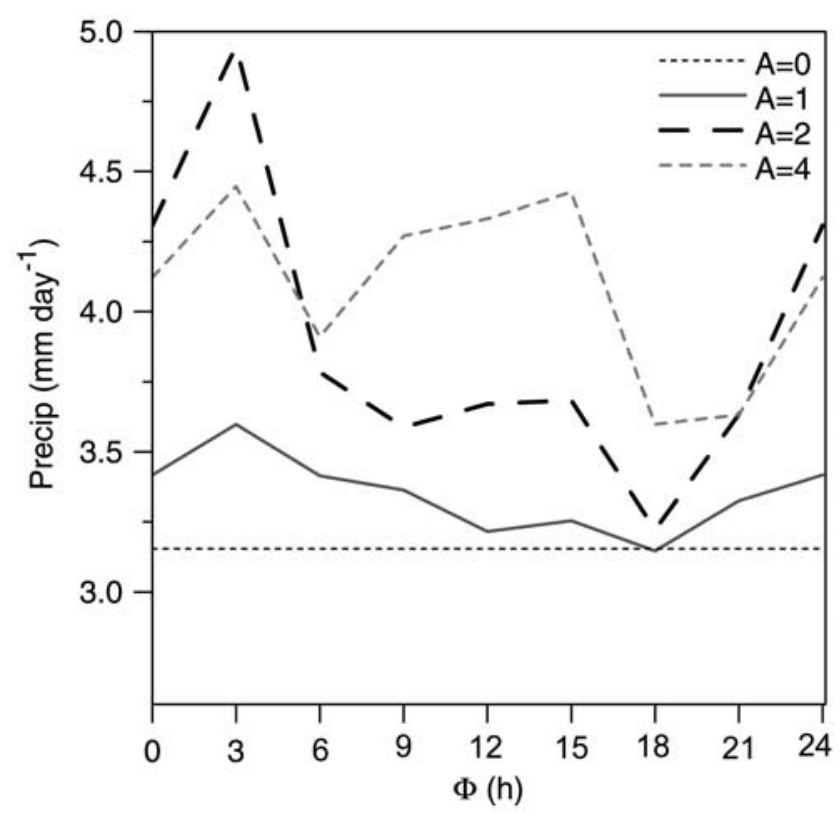

Figure 6. 14-day mean SCM precipitation plotted against phase for increasing diurnal forcing. 

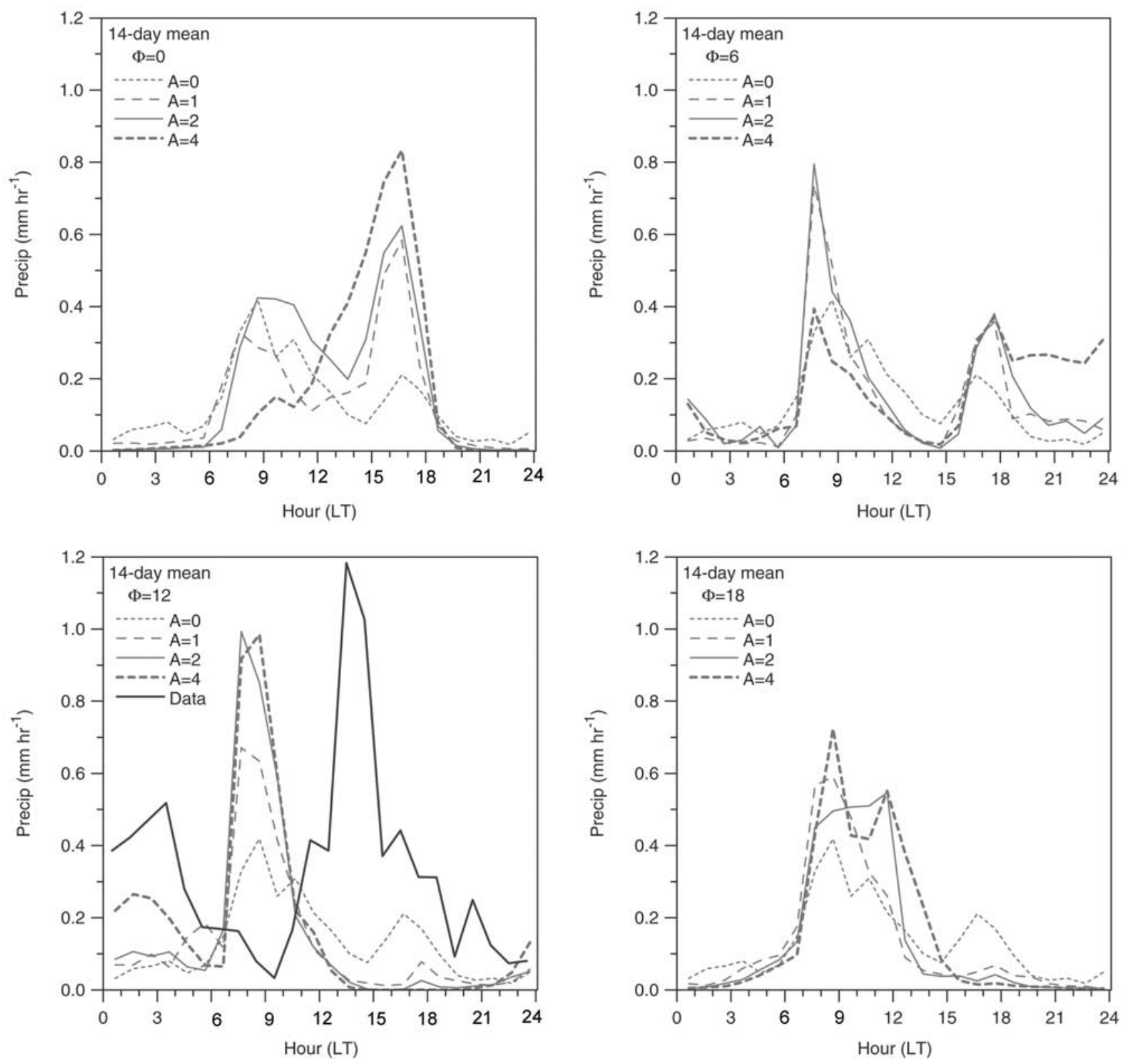

Figure 7. Dependence of diurnal cycle of precipitation on phase and amplitude of omega forcing. Lower left panel shows also the observed mean diurnal cycle from Figure 1.

line, independent of phase, is the control model integrated in time with no omega forcing, that is $\mathrm{A}=\mathrm{M}=0$, and is shown as a reference baseline. The addition of periodic forcing generally increases precipitation (by increasing $\mathrm{SW}_{\text {net }}, \mathrm{R}_{\text {net }}$ and LH, not shown), but the increase depends on phase $\Phi$. For $\mathrm{A}=1,2$, evaporation and precipitation peak for $\Phi=3$, and are a minimum for $\Phi=18$. It is clear however from the $\mathrm{A}=4$ plot that as $\mathrm{A}$ increases further, the behavior is nonlinear. As we shall see later the diurnal phasing of the precipitation shifts dramatically with $\Phi$ and A, and this has a significant impact on $\mathrm{SW}_{\text {net }}$ and $\mathrm{LH}$.

\subsection{Impact of Phase of Forcing on Diurnal Cycle of Precipitation}

[16] Figure 7 shows how phase and amplitude of the diurnal omega forcing affect the diurnal cycle of 14-day mean total precipitation. The plots are for $\Phi=0,6,12$ and
18; all are with $\mathrm{M}=0$. The plot with $\mathrm{A}=0$ is the baseline case, common to all plots, which has a morning precipitation peak. It is clear that the response to diurnal omega forcing depends on the phasing, and is complex. $\Phi=6$, which has subsidence peaking at 0600LT and ascent at 1800LT, gives a bimodal pattern. As A increases, precipitation at sunset increases and then increases into the night hours, while the morning peak, increases for $\mathrm{A}=1$ and 2 and then decreases. $\Phi=12$, with subsidence peaking at noon actually increases the morning peak, as well as producing more precipitation at night as A increases. $\Phi=0$ generally suppresses the morning peak (but not in a regular fashion) and produces an afternoon peak as the diurnal omega forcing increases. $\Phi=18$, representing peak ascent at sunrise, simply splits the morning peak into a second one near noon. Overall, the resilience of the morning precipitation peak in the model is remarkable. 


\subsection{Comparison With Observations}

[17] None of the model curves on Figure 7 shows the observed 1400 LT peak, reproduced from Figure 1 in the lower left panel. This comparison between the mean diurnal cycle in the data and the SCM with idealized diurnal forcing is not entirely straightforward. Observed precipitation occurs in fact on a wide range of time and space scales. Over Amazonia, although diurnally driven precipitation is frequent, the majority of precipitation falls from organized mesosystems, described by Greco et al. [1990] as coastal occurring systems, and basin occurring systems. Our observed mean includes all types of systems, and in particular the rain at night is from large organized mesosystems. The rainfall in this observed mean is $7.4 \mathrm{~mm}$ day $^{-1}$, rather more than shown in Figure 6 for SCM runs with no mean ascent. This is because averaged over all days the ECMWF analysis shows upward mean vertical motion over Amazonia in the rainy season.

[18] It is possible to get an SCM diurnal precipitation peak close to that observed by choosing $\Phi=21$, intermediate between 18 and 0, as shown in Figure 8. However, this idealized forcing with maximum subsidence at LT $=21$ $\mathrm{h}$, is almost out of phase with the mean diurnal cycle of the omega field derived form short-term forecasts of the 3-D model shown in Figure 2. Why the model responds with a midafternoon precipitation peak in response to subsidence peaking in the evening is difficult to unravel, given the complex nonlinear interactions between the diurnal forcing and all the parameterized physical processes. We can speculate that the subsidence in the evening and at night is sufficiently stabilizing, that the morning precipitation peak in the model is suppressed.

\subsection{Impact on Precipitation of Imposing Mean Ascent}

[19] By adding an offset, represented of $M=1,2$ in (1), we can force the SCM with mean vertical motion as well as diurnally varying vertical motion. This gives increasing precipitation for increasing $\mathrm{M}$, as shown in Figure 9a,

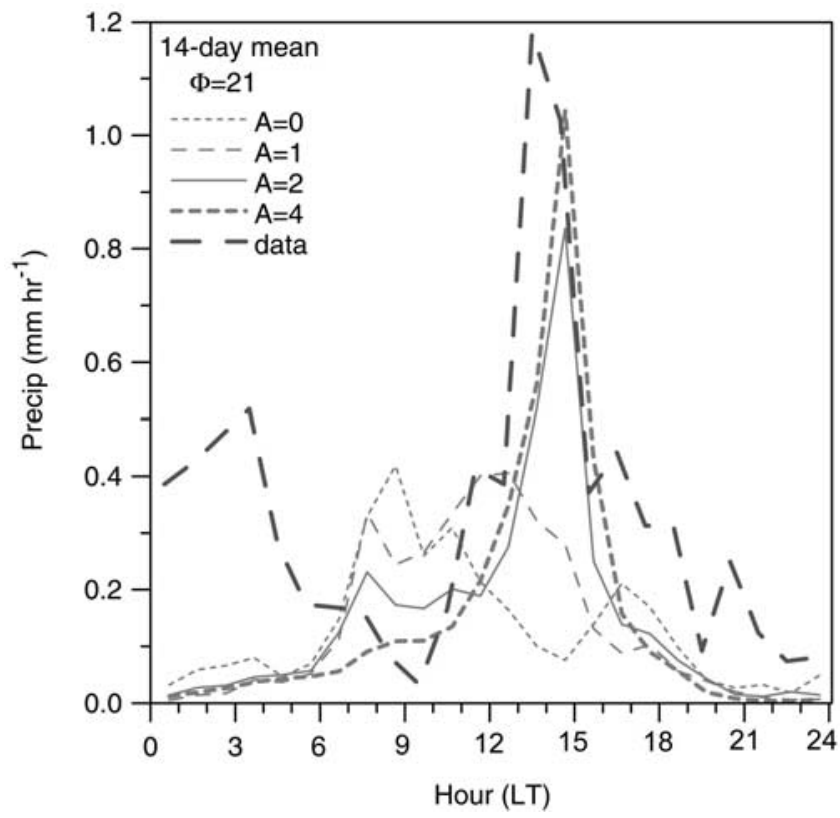

Figure 8. Comparison of observed total precipitation and SCM for omega forcing phase $\Phi=21$ and $\mathrm{M}=0$.

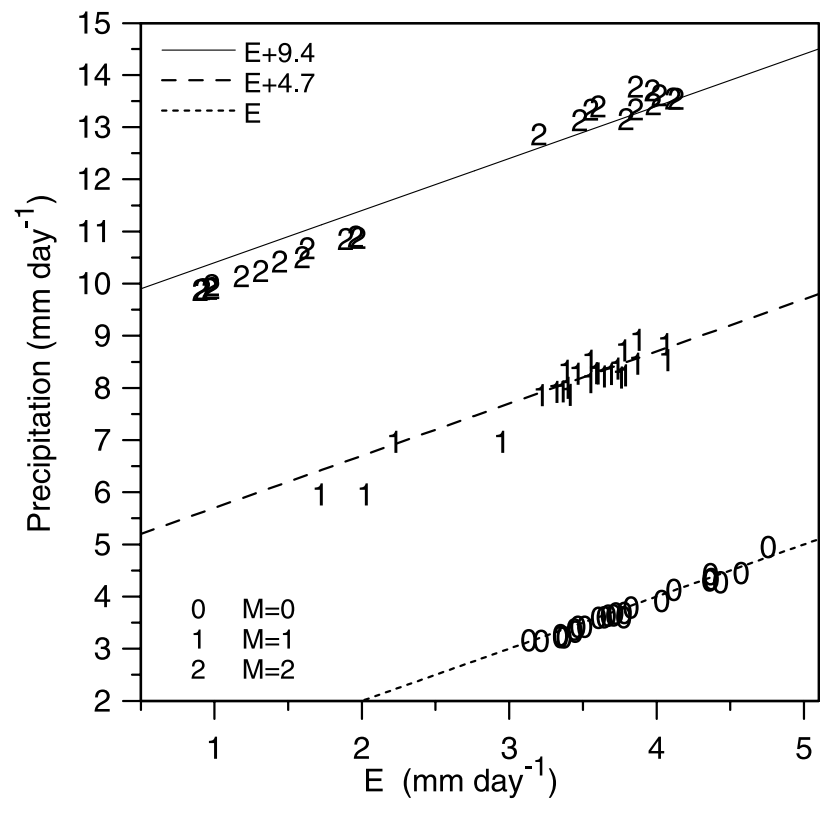

Figure 9a. Scatterplot of 14-day mean precipitation against evaporation for increased mean omega forcing.

which plots 14-day means of total precipitation and evaporation $(\mathrm{E}=\mathrm{LH} / 28.94)$ for all $\Phi$ and $\mathrm{A}$. The data is banded, with the lowest group for $\mathrm{M}=0$ lying close to the dotted 1:1 line (as indicated by Figure 5). For mean ascent $M=1$ the dashed line corresponds to an offset of $+4.7 \mathrm{~mm}$, and for $\mathrm{M}=$ 2 to an offset of $9.4 \mathrm{~mm}$. With no mean forcing, precipitation varies with evaporation of about $4 \mathrm{~mm} \mathrm{day}{ }^{-1}$, and as the mean ascent increases so does mean precipitation. The observed mean precipitation of $7.4 \mathrm{~mm}^{\text {day }}{ }^{-1}$ during the rainy season [Betts and Jakob, 2002] corresponds to M closer to 1 . Note that there are some points on the upper bands with much lower $\mathrm{E}$ of only $1-2 \mathrm{~mm}$ day $^{-1}$ : a few points for $M=1$, and about half the points for $M=2$. Figure $9 \mathrm{~b}$ shows that low mean $\mathrm{SW}_{\text {net }}$ is the cause of the low $\mathrm{E}$

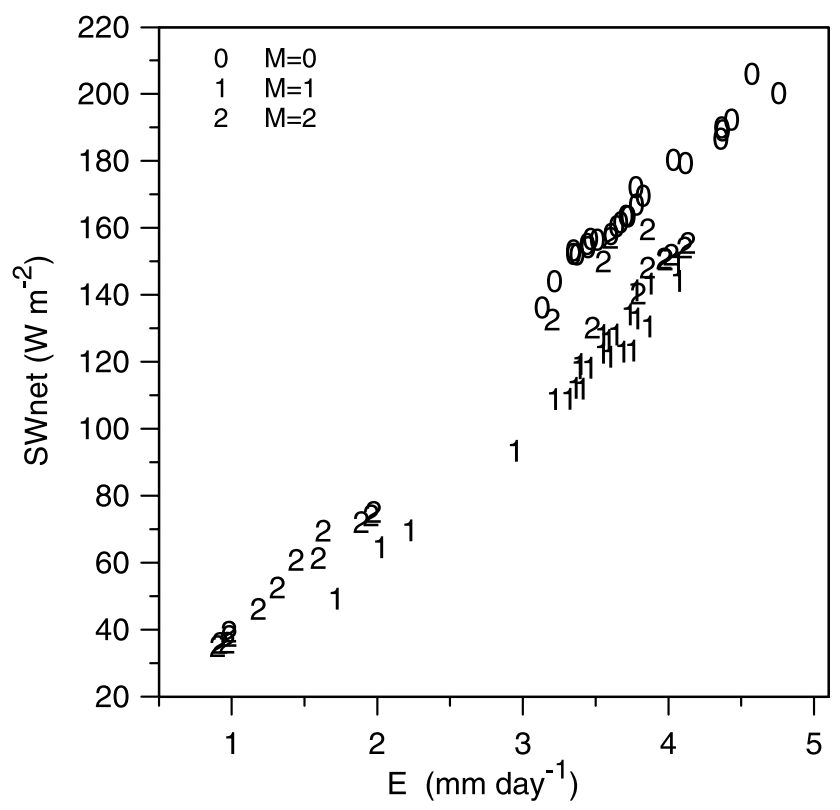

Figure 9b. As Figure 9a for mean net short-wave radiation. 


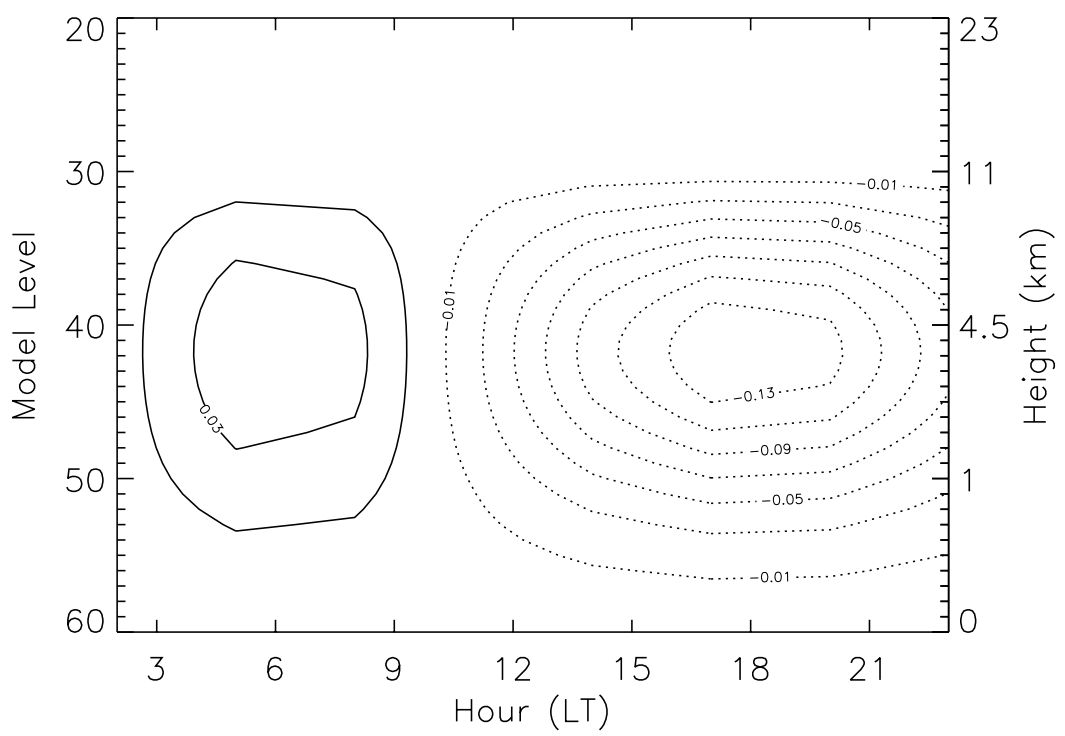

Figure 10a. Idealized omega forcing of $\mathrm{SCM}$ for $\Phi=6, \mathrm{M}=1$, and $\mathrm{A}=2$.

points. What happens is that with larger mean upward motion, some SCM simulations collapse in a few days to $100 \%$ cloud cover, which drastically reduces $\mathrm{SW}_{\text {net }}, \mathrm{R}_{\text {net }}$, and evaporation. At the same time the diurnal cycle of temperature becomes small and the model drifts cooler. We will show an example later.

\subsection{Comparison of Idealized and 3-D Model Forcing}

[20] The mean model omega field shown in Figure 2 for the 29-day average of the 3-D model short-term forecasts can be roughly approximated by the idealized forcing of $\mathrm{M}=1$, $\mathrm{A}=2$, and $\Phi=6$, shown in Figure 10a. Both have the transition between mean descent and ascent in the late morning. Figure 10b compares four curves. Two are 29day ensembles; the heavy solid curve is the ensemble of $12-$ $36 \mathrm{hr}$ forecasts from the full 3-D model, and the dashed curve is the ensemble average of days 1 and 2 of 29 SCM runs, driven by the large-scale forcing from the 3-D model. The light solid line is the day $1-15$ average of a single SCM run driven by the 29-day mean forcing from the 3-D model, and finally the dotted line is a similar SCM run driven by idealized forcing of $\mathrm{M}=1, \mathrm{~A}=2$, and $\Phi=6$. The precipitation structure with a double peak, morning and evening, is common to all four. The ensembles have rather a weaker midday minimum than the single SCM runs, because thay represent an average of many diverse days in which the large-scale forcing has considerable variability. It is clear that the 3-D model and the SCM runs, whether driven by composites of the model forcing or by idealized forcing of similar amplitude and phase, give a consistent picture. However, the basic question as to whether the diurnal phase of the model omega field is "correct" has not been answered. In addition, none of the SCM runs presented so far give insight into how the control model might be modified to improve the diurnal cycle of precipitation.

\subsection{SCM Temperature, Lifting Condensation} Level (LCL), and Precipitation Diurnal Cycles

[21] So far we have shown only 14-day means for the SCM runs. The time sequences give more insight into the impact of the relative phasing of solar and omega forcing. In addition, since there is no horizontal advection, the drift with time of temperature indicates the imbalance of the radiation field associated with the different phasing of the cloud field. Figure 11 shows examples of the temporal structure of our 15-day SCM runs for $\mathrm{M}=0, \mathrm{~A}=4$ for three selected phases $\Phi=0,12$ and 18. For $\Phi=12,2-\mathrm{m}$ temperature (upper panel) drifts warmer with time of integration, while the diurnal variation of $\mathrm{P}_{\mathrm{LCL}}$ (the pressure height to the LCL, which is closely related to relative humidity [see, e.g., Betts, 2000], and total precipitation is quite regular. The runs with $\Phi=6,9$ and 15 (not shown) are broadly similar. The run with $\Phi=18$ (and $\Phi=21$, not shown), drifts very slightly cooler and stays nearer to

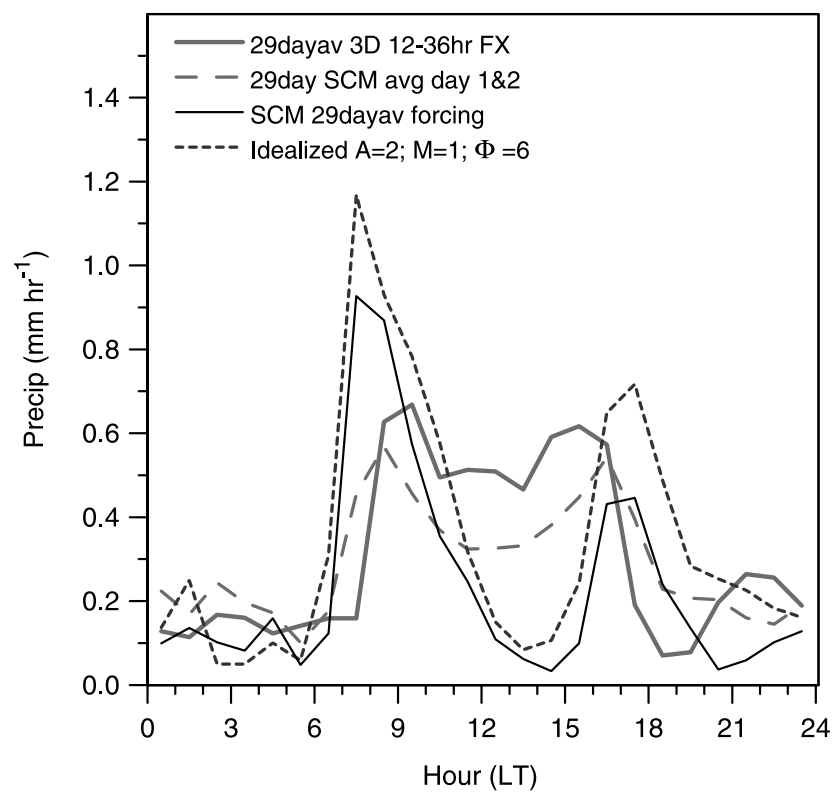

Figure 10b. Comparison of 29-member ensembles of 3-D short-term forecasts and SCM runs, with single SCM runs driven by mean GCM forcing and idealized forcing. 

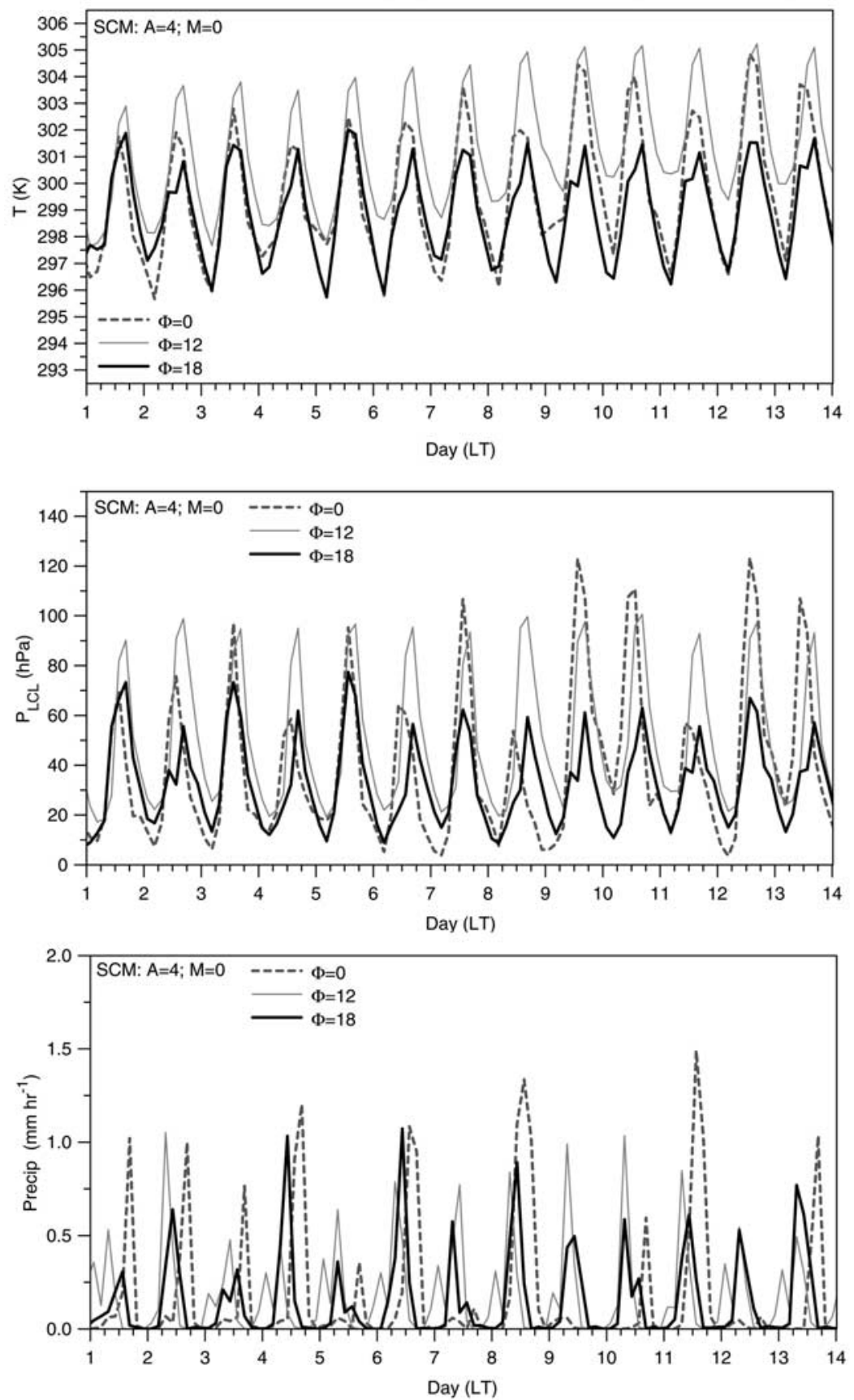

Figure 11. $\mathrm{SCM}$ control runs of $\mathrm{T}, \mathrm{P}_{\mathrm{LCL}}$ and precipitation with $\mathrm{A}=4, \mathrm{M}=0$.

saturation during the daytime. The run with $\Phi=0$ however (and $\Phi=3$, not shown) oscillates between a warmer (and less saturated) and a colder diurnal cycle, in which some days have large precipitation (days 4, 6, 8, 11, and 13), interspersed with days with very little rain. The response with $\mathrm{M}=0$ and $\mathrm{A}=2$ is similar (not shown).

[22] It is clear that the SCM has a complex range of responses, as the relative phase of the diurnal solar forcing and the omega forcing changes. Some aspects are relatively easy to understand. The run with $\Phi=12$ has maximum noon subsidence, so the upward drift of temperature is consistent with the suppression of daytime cloudiness, and a larger net radiation flux. These runs also have the most nighttime rain, as well as a sharp precipitation peak after sunrise (Figure 7). The run with $\Phi=18$ has rain throughout the daytime period, more cloud cover, and less $\mathrm{R}_{\text {net }}$, which is consistent with the cooler "equilibrium" temperature. However it is not clear why, for $\Phi=0$ when upward daytime omega forcing is in phase with the solar forcing, the SCM prefers a nearly 2-day mode.

[23] Figure 12 shows the same three plots for mean ascent $M=1$, and in addition, the case for $\Phi=21$. For $\Phi=12$, the SCM maintains a nearly periodic warm diurnal temperature and unsaturated structure, but for $\Phi=0$, and especially for $\Phi=18$, the model drifts cooler and more saturated under the influence of mean upward forcing, although there is some recovery in the second week. Finally, the $\Phi=21$ case saturates and stays cold and cloudy, because the strong 

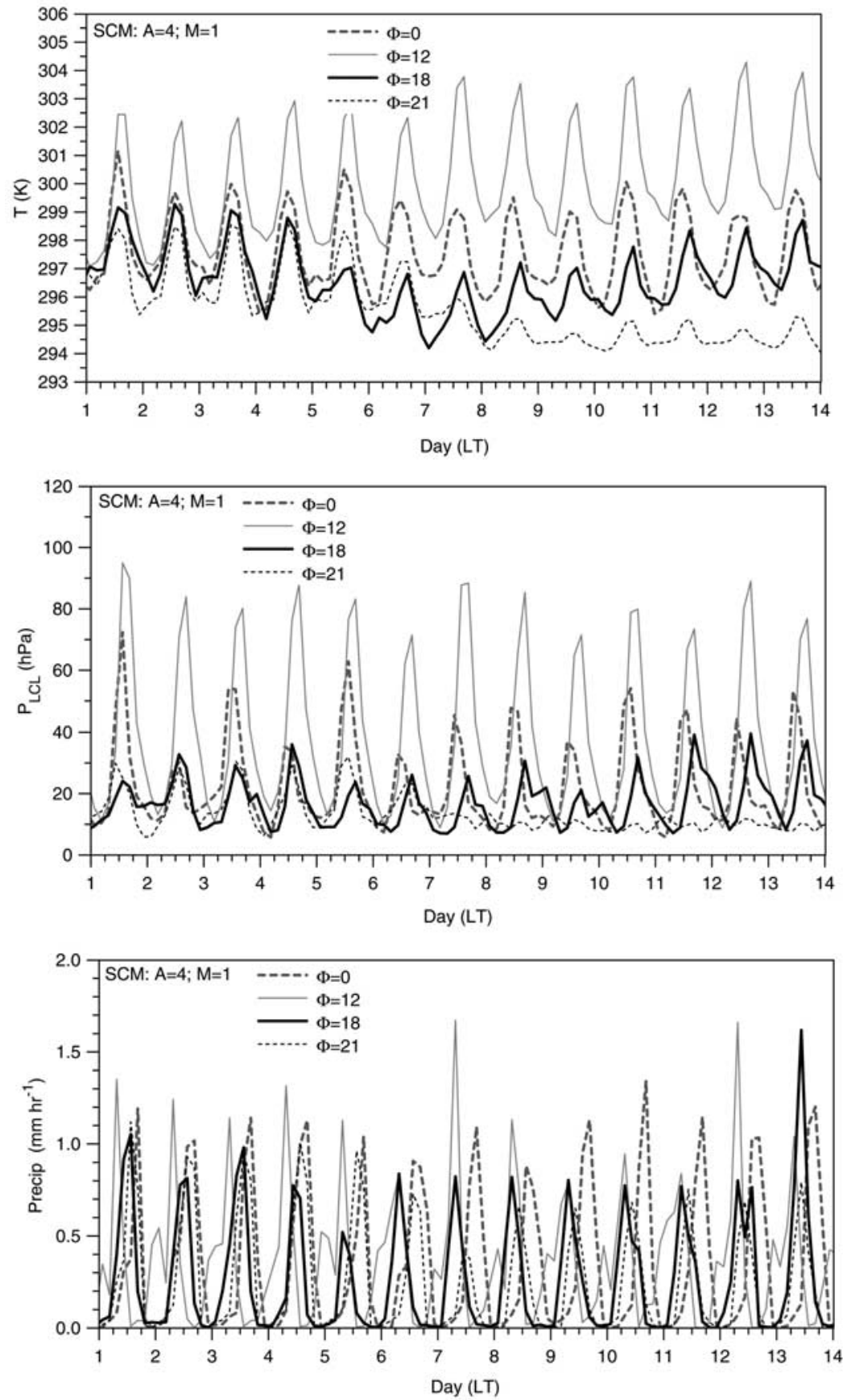

Figure 12. As Figure 11 for $M=1$, with $\Phi=21$ in addition.

daytime ascent results in a transition to stratiform precipitation and solid cloud cover (see below). With mean ascent, the near 2-day mode is less apparent. Although we have only shown a small subset of the SCM runs, they are representative of the range of model responses to changing $\Phi, \mathrm{M}$, and $\mathrm{A}$.

\subsection{Impact of Phase of Diurnal Omega Forcing} on Convective and Stratiform Rain

[24] It is clear from Figure 12 that no true steady state is achieved in general, and, for example, for $\Phi=21$ there is a distinct transition around day 6. Figure 13 summarizes the transition that the $\mathrm{SCM}$ makes with $\mathrm{M}=1$ and $\mathrm{A}=4$ in a different way, showing the averages over days $6-15$. The upper panel shows convective and large-scale precipitation (CP and LSP) on the left-hand-scale, and $\mathrm{R}_{\text {net }}$ on the scale on the right, plotted against the phase of the omega forcing (with phase $=0$ replicated at 24). The cooler more saturated states for omega phase of 18 and 21 are associated with a shift from convective precipitation to large-scale precipitation and a corresponding sharp fall of $\mathrm{R}_{\text {net }}$. The transition between $\Phi=15$ to $\Phi=18$ is abrupt. For $\Phi=15$, the SCM has a sharp midmorning peak of convective rain with very little large-scale precipitation, and $R_{\text {net }}$ is little affected. However for $\Phi=18$ (ascent peaking at sunrise), large-scale rain starts before sunrise in phase with the omega forcing as 

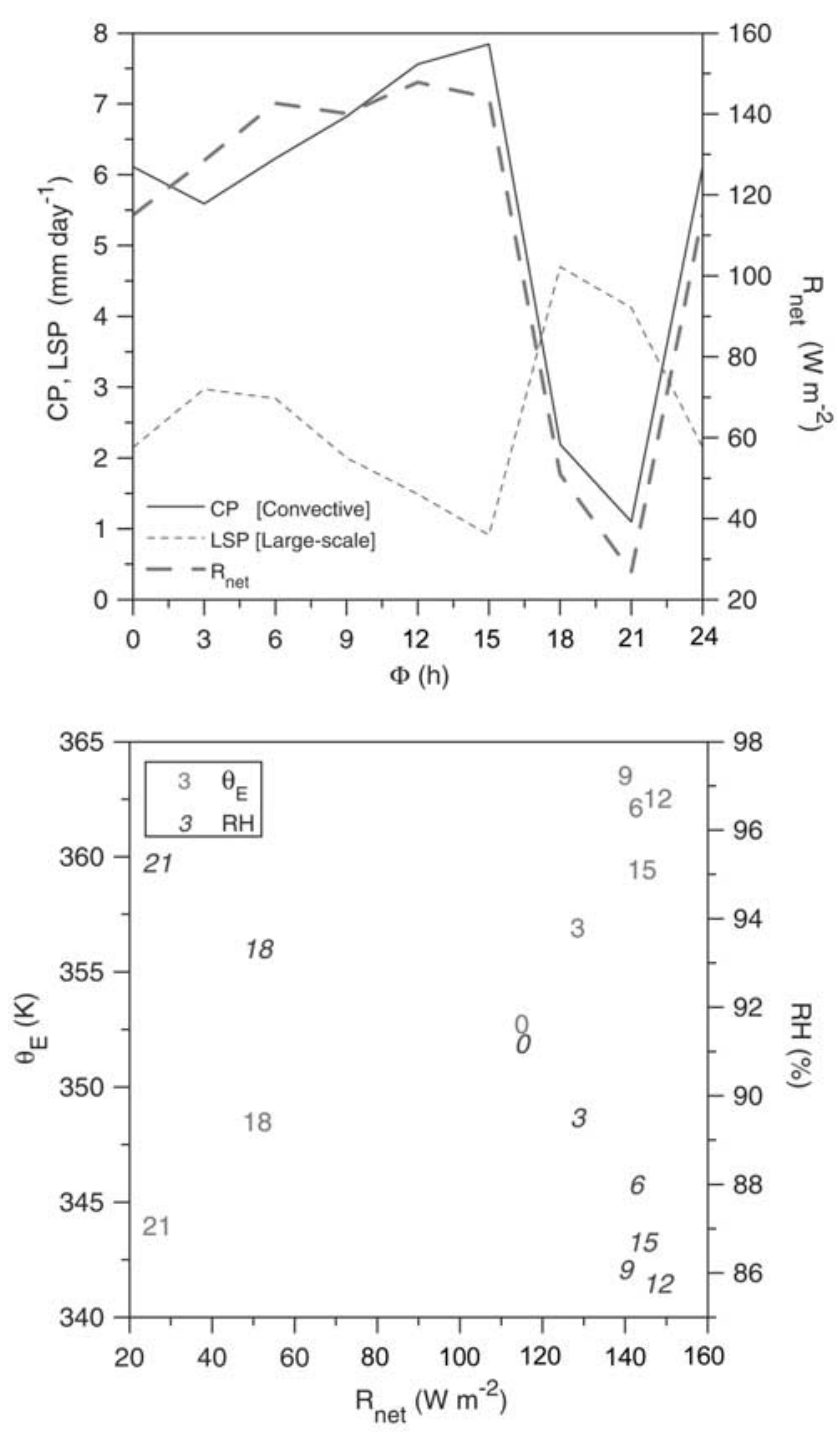

Figure 13. Dependence of convective and large-scale precipitation (mean for days $6-15$ ) and $R_{\text {net }}$ on phase (upper panel), and 2-m $\theta_{\mathrm{E}}$ and $\mathrm{RH}$ on $\mathrm{R}_{\text {net }}$ (lower panel).

the atmosphere reaches saturation, and there is very little convective rain. This shift from convective to large-scale rain, and its associated cloud field, dramatically reduces the net radiation at the surface. For $\Phi=21$, the large-scale precipitation peak shifts to 1030 LST (not shown) slightly behind the peak in the omega forcing.

[25] The lower panel shows how the drop of $R_{\text {net }}$ at the surface with increased large-scale cloud cover leads to a drop of 2-m $\theta_{\mathrm{E}}$ (again an average from day 6-15) from around $360-365 \mathrm{~K}$ to only $344 \mathrm{~K}$ for $\Phi=21$ (the numeral indicates the phase). The corresponding $\mathrm{RH}$ is also shown (scale on right), indicating that as $\mathrm{R}_{\text {net }}$ falls, the near-surface air moves closer to saturation.

[26] With larger mean ascent, $M=2$, two distinct modes with high and low precipitation can be seen in Figure 9a. Figure 14 for $\mathrm{M}=2$ and $\mathrm{A}=4$ shows these correspond to modes with convective and stratiform rain, and depend on the phase of the diurnal forcing. In comparison with Figure 13 , the increased mean forcing has produced a response that is now almost symmetric in the diurnal omega forcing.
Daytime subsidence for $\Phi=6$ to 18 gives mostly daytime convective rain and high $\mathrm{R}_{\text {net }}$ (though a little lower than in Figure 13), while $\Phi=21,0$ and 3 gives almost entirely stratiform rain, peaking in the daytime, and very low $\mathrm{R}_{\text {net }}$. The reduced amount of stratiform rain for $\Phi=6$ to 18 is mostly at night (not shown), which is consistent with the large-scale ascent peaking during the nighttime hours.

[27] The lower panel of Figure 14 shows that the surface energy balance splits into two distinct modes, with $\Phi=6$ to 15 corresponding high $R_{\text {net }}$ and $2-\mathrm{m} \theta_{\mathrm{E}}$, and $\Phi=21$ and 0 to very low $R_{\text {net }}$ and $\theta_{\mathrm{E}}$, with $\Phi=3$ and 18 making the transition. However, note that between $\Phi=6$ and 15, there is quite a spread of mean $\mathrm{RH}$ (which is related to mean boundary layer subsaturation), but not of $\mathrm{R}_{\mathrm{net}}$ and $\theta_{\mathrm{E}}$. RH is a minimum for $\Phi=12$ (subsidence peaking at noon), and this corresponds also to the highest daytime cloud-base.

\section{Assessment of SCM Runs and Conclusions}

[28] We started this work to understand and try to correct the diurnal phase error in convective precipitation in the ECMWF forecast model. Although we have made progress
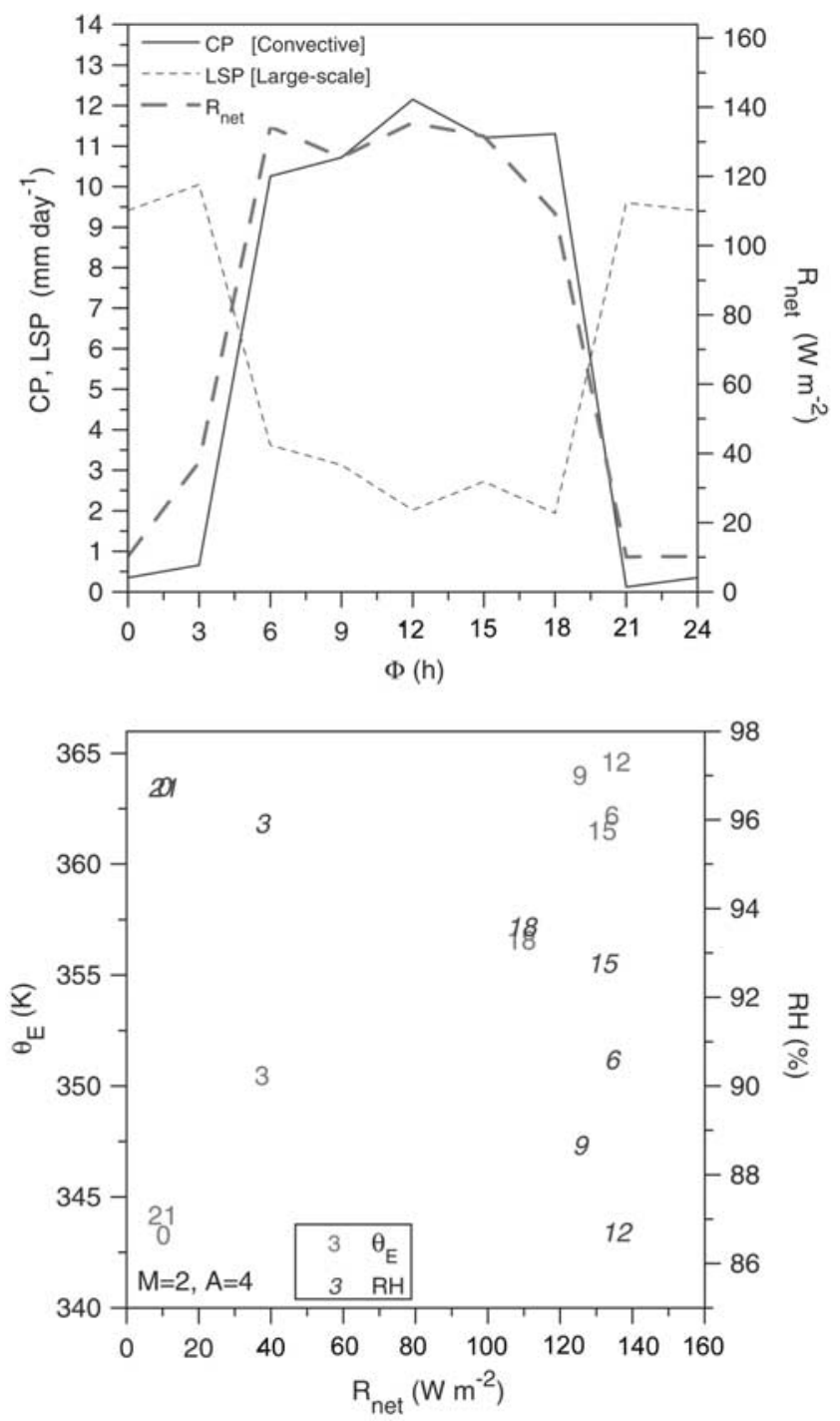

Figure 14. As Figure 13 for $M=2, A=4$. 
in understanding the complexity of the problem, we have so far not been able to construct a convective parameterization, within the framework of the current ECMWF mass flux formulation, that gives the observed diurnal cycle of precipitation. So this paper is an summary of what we have learnt.

[29] The first question we addressed is whether SCM models, in which specified large-scale forcing is used to drive a 1-D model, are a useful simplification of the fully three-dimensional system? Here lies also the heart of the convection parameterization problem; namely, whether, particularly in the tropics, the large-scale fields and the convective processes can be uncoupled? In the case of the diurnal cycle, we ask whether the diurnal cycle of the largescale omega field in the 3-D model has significant errors resulting from the errors in the diurnal phase of the precipitation? We found that both short-term forecasts and long runs of the model had similar diurnal cycles of omega with a subsidence maximum near sunrise and an ascent maximum in the late afternoon. While this is a plausible diurnal structure, driven perhaps on the large-scale by radiative cooling at night, we have no confirmation, independent of the model, that it is correct. We experimented with many changes to the convective parameterization (which we have not shown here), but found that both the diurnal cycle of the omega field and precipitation in the model were very resistant to change. Nonetheless, we found that the SCM model is a useful simplified version of the full $3-\mathrm{D}$ model because it has a similar diurnal error signature, so we used it to explore more fully the response of the convective parameterization to both idealized forcing and large-scale forcing extracted for a grid-point in Rondônia from short-term forecasts of the global model.

[30] Since the erroneous morning precipitation peak occurs near the time of peak subsidence in the model (and it can also be reproduced with similar idealized diurnal omega forcing), we concluded that it is likely that it is the model parameterizations that are the source of this error, rather than an error in the diurnal omega cycle. The immediate cause is that as soon as the stable boundary layer is penetrated a few hours after sunrise, the deep convection scheme is triggered, as it "sees" a troposphere, which is very unstable up to the freezing level in the middle troposphere. However, we were unable to remove this morning precipitation peak in 15-day SCM runs, by modifications to the current ECMWF convection scheme (so we did not even shown these results). For example, increasing the entrainment sufficiently in the shallow convection scheme, and calling the shallow scheme before the deep scheme, will suppress early deep convection on the first day, but it simply returns early on the second day, since without sufficient precipitation, the lower tropospheric instability is increased. Changing the convective closure on the shallow scheme, from moist static energy balance at each time step, to a CAPE closure similar to that of the deep scheme, alters the mixed layer equilibrium, but also had little impact on the mean diurnal cycle of precipitation. We realized that the entire diurnal cycle matters. Figure 1 suggests that the ECMWF model may underestimate precipitation at night, which could stabilize the morning boundary layer. However, most of the observed nighttime precipitation is from major organized convective systems, and it may be that these large systems are under-represented in the model.
Similarly, errors in the stabilization in the late afternoon (caused by for example too weak downdrafts, which in nature stabilize the atmosphere by bringing down cool, dry air to the boundary layer) might be the cause of the early deep convection the following morning. However the present formulation of the downdraft scheme does not facilitate simple changes. Even the afternoon organization into mesoscale convective bands (which are not represented in the model), with mesoscale updrafts and downdrafts, may play a role by increasing in some sense precipitation efficiency, and stabilizing the atmosphere. More generally, the timescale for the growth of the tropical shallow cumulus BL, which evolves for about 3-4 hours every morning, is not properly represented in the model. The shallow convection is simply closed using a subcloud layer balance of moist static energy at every time step (15 mins), and its depth is found by an entraining moist adiabat (with specified entrainment), which is poorly constrained in a highly unstable atmosphere. Yet another possibility is that evaporation of rain from the first cumulus congestus, often seen on radar in midmorning, stabilize the atmosphere and delay deep convection. Thus at this time, a development path is not clear in terms of present simplified parametric framework, and other approaches will be explored.

[31] The 15-day SCM runs with controlled periodic forcing proved very valuable in understanding the complexity of the coupling between the forcing and the diurnal phase, as well as the links between the radiative forcing, the surface fluxes and the precipitation. In 14-day averages, precipitation is tightly coupled to the surface evaporation, and hence to net radiation, net short-wave radiation and cloud cover. We realized that the so-called short-wave cloud feedback in climate simulations is fundamentally a diurnal problem, related to the diurnal phasing of convection, clouds and the type of precipitation. The SCM runs drifted to a warmer or cooler "climate" depending on the phase of the omega forcing (which we specified) with respect to the diurnal solar forcing. However the SCM runs also showed two distinct modes. With both strong mean ascent and diurnal omega forcing, ascent peaking in the daytime gave stratiform rain with large cloud cover and very low mean surface $R_{\text {net }}$, while daytime subsidence and ascent at night gave strong daytime convective precipitation, lower cloud cover and correspondingly much larger $\mathrm{R}_{\text {net }}$, and weak nighttime stratiform precipitation. Although this response may be specific to the ECMWF model and its parameterizations (and we have shown the convective parameterization does not give the correct diurnal phase of precipitation), it is clear that attention needs to be paid the partition of precipitation into convective and stratiform over the diurnal cycle.

[32] Acknowledgments. Alan Betts acknowledges support from NASA under grant NAS5-8364 and NAS5-11578 and from NSF under grant ATM-9988618, and from ECMWF for travel. We thank the reviewers for their helpful suggestions.

\section{References}

Beljaars, A. C. M., and A. K. Betts, Validation of the boundary layer representation in the ECMWF model, in ECMWF Seminar Proceedings, 7-11 Sept. 1992, Validation of Models Over Europe, vol. II, pp. 159195, Eur. Cent. for Med.-Range Weather Forecasting, Reading, UK, 1993. 
Betts, A. K., Idealized model for equilibrium boundary layer over land, J. Hydrometeorol., 1, 507-523, 2000.

Betts, A. K., and C. Jakob, Evaluation of the diurnal cycle of precipitation, surface thermodynamics, and surface fluxes in the ECMWF model using LBA data, J. Geophys. Res., 107(D20), 8045, doi:10.1029/ 2001JD000427, 2002.

Betts, A. K., and M. J. Miller, A new convective adjustment scheme, II, Single column tests using GATE-wave, BOMEX, ATEX, and Arctic airmass data sets, Q.J.R. Meteorol. Soc., 112, 693-710, 1986.

Betts, A. K. and P. Viterbo, Basin-scale hydrologic budgets from ERA-40 for the Mississippi, Mackenzie and Amazon rivers, paper presented at 16th Conference On Hydrology, Am. Meteorol. Soc., Orlando, Fla., 1417 Jan., 2002

Betts, A. K., P. Viterbo, and E. Wood, Surface energy and water balance for the Arkansas-Red river basin from the ECMWF reanalysis, J. Clim., 11, 2881-2897, 1998.

Betts, A. K., J. H. Ball, and P. Viterbo, Basin-scale surface water and energy budgets for the Mississippi from the ECMWF reanalysis, J. Geophys Res., 104, 19,293-19,306, 1999.

Betts, A. K., J. Fuentes, M. Garstang, and J. H. Ball, Surface diurnal cycle and boundary layer structure over Rondônia during the rainy season, J. Geophys. Res., 107(D20), 8065, doi:10.1029/2001JD000356, 2002.

Emanuel, K. A., and D. J. Raymond, The Representation of Cumulus Convection in Numerical Models, Meteorol. Monogr., 24, no. 46, Am. Meteorol. Soc., Boston, Mass., 1993.

Ghan, S., et al., A comparison of single column model simulations of summertime midlatitude continental convection, J. Geophys. Res., 105, $2091-2124,2000$

Greco, S., R. Swap, M. Garstang, S. Ulanski, M. Shipman, R. C. Harriss, R. Talbot, M. O. Andreae, and P. Artaxo, Rainfall and surface kinematic conditions over central Amazonia during ABLE 2B, J. Geophys. Res., $95,17,001-17,014,1990$.

Gregory, D., J.-J. Morcrette, C. Jakob, A. C. M. Beljaars, and T. Stockdale, Revision of convection, radiation and cloud schemes in the ECMWF integrated forecast system, Q.J.R. Meteorol. Soc., 126, 1685-1710, 2000

Halverson, J. B., T. Rickenbach, B. Roy, H. Pierce, and E. Williams, Environmental characteristics of convective systems during TRMM-LBA, Mon. Weather Rev., 130, 1493-1509, 2002.

Holtslag, A. A. M., and B. A. Boville, Local versus non-local boundary layer diffusion, J. Clim., 6, 1825-1842, 1993

Kuo, H. L., On formation and intensification of tropical cyclones through latent heat release by cumulus convection, J. Atmos Sci., 22, 40-63, 1965.

Liu, Y., D.-L. Zhang, and M.K. Yau, A multiscale numerical simulation on hurricane Andrew (1992), I Explicit simulation and verification, Mon Weather Rev., 125, 3073-3093, 1997.

Manabe, S., and R. Strickler, Thermal equilibrium of the atmosphere with a convective adjustment, J. Atmos Sci., 21, 361-385, 1965.
Negri, A. J., L. Xu, and R. F. Adler, A TRMM-calibrated infrared rainfall algorithm applied over Brazil, J. Geophys. Res., 107(D20), 8048, doi:10.1029/2000JD000265, 2002.

Petersen, W. A., S. W. Nesbitt, R. J. Blakeslee, R. Cifelli, P. Hein, and S. A. Rutledge, TRMM observations of intraseasonal variability in convective regimes over the Amazon, J. Clim., 15, 1278-1294, 2002.

Randall, D. A., K.-M. Xu, R. J. C. Somerville, and S. Iacobellis, Singlecolumn models and cloud ensemble models as links between observations and climate models, J. Clim., 9, 1683-1697, 1996.

Randall, D. A., J. Curry, P. Duynkerke, S. Krueger, M. Moncrieff, B. Ryan, D. Starr, M. Miller, W. Rossow, G. Tselioudis, and B. Wielicki, Confronting models with data: The GEWEX cloud systems study, Bull. Am. Meteorol. Soc., in press, 2002.

Rutledge, S. A., W. A. Petersen, R. C. Cifelli, and L. D. Carey, Early results from TRMM-LBA: Kinematic and microphysical characteristics of convection in distinct meteorological regimes, paper presented at 24th Conference on Hurricanes and Tropical Meteorology, Am Meteorol. Soc., Ft. Lauderdale, Fla., 29 May to 2 June, 2000.

Silva Dias, M. A. F., et al., Clouds and rain processes in a biosphere atmosphere interaction context in the Amazon Region, J. Geophys. Res., 107(D20), 8072, doi:10.1029/2001JD000335, 2002.

Stendel, M., and K. Arpe, Evaluation of the hydrological cycle in reanalyses and observations, ECMWF Reanalysis (ERA-15) Proj. Rep. Ser., 6, Eur. Cent. For Medium-Range Weather Forecasts, Reading, UK, 1997.

Sud, Y. C., D. M. Mocko, G. K. Walker, and R. D. Koster, Influence of land surface fluxes on precipitation: Inferences from simulations forced with four ARM-CART SCM datasets, J. Clim., 14, 3666-3691, 2001.

Tiedtke, M., A comprehensive mass flux scheme for cumulus parametrization in large-scale models, Mon. Weather Rev., 117, 1779-1800, 1989.

Van den Hurk, B. J. J. M., P. Viterbo, A. C. M. Beljaars, and A. K. Betts, Offline validation of the ERA40 surface scheme, ECMWF Tech. Memo, 295, 43 pp., Eur. Cent. for Medium-Range Weather Forecasts, Reading, UK, 2000

Viterbo, P., and A. C. M. Beljaars, An improved land-surface parameterization in the ECMWF model and its validation, J. Clim., 8, 2716-2748, 1995.

Wu, X., and M. W. Moncrieff, Sensitivity of single-column models to convective parameterizations and initial conditions, J. Clim., 14, $2563-$ 2582, 2001.

Zhang, G. J., and N. A. McFarlane, Sensitivity of climate simulations to the parameterization of cumulus convection in the Canadian Climate Centre general circulation model, Atmos. Ocean, 33, 407-446, 1995.

A. K. Betts, Atmospheric Research, 58 Hendee Lane, Pittsford, VT 05763, USA. (akbetts@aol.com)

C. Jakob, BMRC, 150 Lonsdale Street, GPO Box 1289K, Melbourne, VIC 3001, Australia. (c.jakob@bom.gov.au) 